\title{
The importance of User Centered Design methods applied to the design of a new workstation: a case study
}

\author{
Ronaldo Duschenes ${ }^{\mathrm{a}}$, Andressa Mendes $^{\mathrm{a}}$, Adriana Betiol $^{\mathrm{b}}$ and Suzana Barreto ${ }^{\mathrm{c}}$ \\ âFlexiv Móveis,duschenes@flexiv.com.br, andressa@flexiv.com.br,Curitiba,Paraná, Brazil \\ ' Interfácil Usabilidade de Sistemas Ltda, adriana@interfacilbr.com.br, Curitiba, Paraná, Brazil \\ 'Universidade Estadual de Londrina, suzanabarreto@onda.com.br, Londrina, Paraná, Brazil
}

\begin{abstract}
This paper presents a case study of the application of user centered design methodologies in the product development for a line of ergonomic office furniture. The study aimed to analyze the experience of using a workstation from the perspective of two groups of users, installers and end users. The observation of users in their natural context of use not only allowed the development team to identify key needs and strategies of the users, transforming them into design solutions, but mainly it warned them of the importance and impact of user involvement in the product development cycle.
\end{abstract}

Keywords: User-centered design, user experience, usability, office furniture

\section{Introduction}

"User-Centered Design" is a development approach that focuses primarily on the users, their needs, strategies and requirements. By applying knowledge and techniques of human factors, ergonomics and usability, this approach allows designing interactive products and systems that will be more useful, easy to use and that will delight users [5].

ISO 9241 (Ergonomics of human-system interaction) on part 210 (Human-centered design for interactive systems) [4] recommends that user involvement be a common practice in companies that design interactive products and systems. The user may be involved in different stages of the project development cycle as a source of information, as an evaluator or even as co-author of design solutions [2].

"Contextual Analysis" is a method that consists of observing users representatives of the target audience using the product and performing real tasks in their natural work environment $[1,3]$.

This study applied two techniques of contextual analysis -contextual observation and interviews- to evaluate the experience of using a workstation that's part of a new line of office furniture.

\section{Methodology and process}

The studied workstation was designed for six people, and was installed in the information technology department of a company. The target users were divided into two groups, the furniture installers and the end users.

The team involved in this project was comprised of eight people from the office furniture design company, including the areas of design, marketing and sales, as well as two members of its board, and a human factors expert from a usability consulting company.The project was conducted during six months and was executed in four steps as detailed below.

\subsection{Context of use analysis}

The first phase of this project was the observation of six users using the old workstation that was in use at the company for three years. During four days, 
eight designers, marketing and sales professionals, under the guidance of a usability consultant, observed and interviewed the users in their workplace. Observers took note on how users interacted with the workstation, with the work environment and with each other, to identify critical points in the use of the product such as the organization of office supplies, documents and personal belongings.

Observers have formed teams of two people who carried out the research on different days. They spent around two hours on site with the constant concern of not interfering in the users' routine. Each observer took his notes individually and also took pictures of the most significant users' strategies and situations of use. Each team prepared a presentation with the results of this step to be discussed during a workshop. The usability expert and two board members of the company were also at the workshop. The result of this workshop was consolidated into a final report which brought together all the observations collected about the context of use. Based on this final report, it was possible to specify the design of the new workstation to be sent to the users.

\subsection{Follow-up of production, transportation and in- stallation of the new workstation}

This step included the assessment of internal processes such as production, delivery and assembly by observing the second group of users, assemblers and installers of the product (three users responsible for assembling the workstation and two users responsible for installation of electrical and logical wiring). These users were observed initially in the plant during the stage of pre-assembly of the product and later in the expedition. The installers were then followed during all steps of transporting the product to the place of delivery.

Disassembling the old station and mounting the new station were observed by two designers, a marketing professional and a usability consultant. All observers individually made notes and took pictures of the main strategies of the users.

During this stage it was observed how the improvements designed for the new workstation, such as increased modularity and new components for passage of wiring, impacted on the assembly team.

After assembling the new workstation, an interview was conducted with the assembly team to assess their opinion about the experience of use in relation to setting up the new workstation compared to the previous model.

\subsection{Analysis of users' first impression}

The new workstation was mounted on a Friday evening after working hours so as not to disturb the routine of the workstation users. On Monday morning, two designers followed the arrival of the six occupants of the workstation to observe their initial reaction to the new product.

The goal was to evaluate the initial perception of the user in relation to new product and watch the interaction with the new workstation looking at how the equipment and personal items were installed and if all components and accessories were easy to identify and use without help or instruction.

The observers took notes and pictures from the main strategies of the users.

The results gathered in steps two and three were presented and discussed during a workshop in which participated all people involved in this project.

\subsection{Analysis of the user experience with the new} product after three months of use

The same process of step 1 was applied again three months after the installation of the new workstation to analyze how the six users were using the new product. Four designers, two marketing professionals and two sales professionals observed and interviewed users during four days. All observes took individual notes and also registered the main usage scenarios in pictures.

Finally, the usability consultant conducted interviews with the six users to evaluate their preference in relation to the experience of use of the two versions of the workstation. The interviews, lasting one hour each, were conducted during three days due to the agenda of the participants. After the interview each participant answered a satisfaction questionnaire developed for this study. All interviews were videotaped.

The results of observations of each team and the consultant's work were presented and discussed at a final workshop. Figure 1 summarizes the phases in this research. 


\begin{tabular}{l} 
Step 1 \\
Context of use \\
analysis \\
$\begin{array}{l}\text { - Specification } \\
\text { of the context } \\
\text { ofuse } \\
\text { - Specification } \\
\text { oflhe new } \\
\text { product }\end{array}$ \\
\hline
\end{tabular}
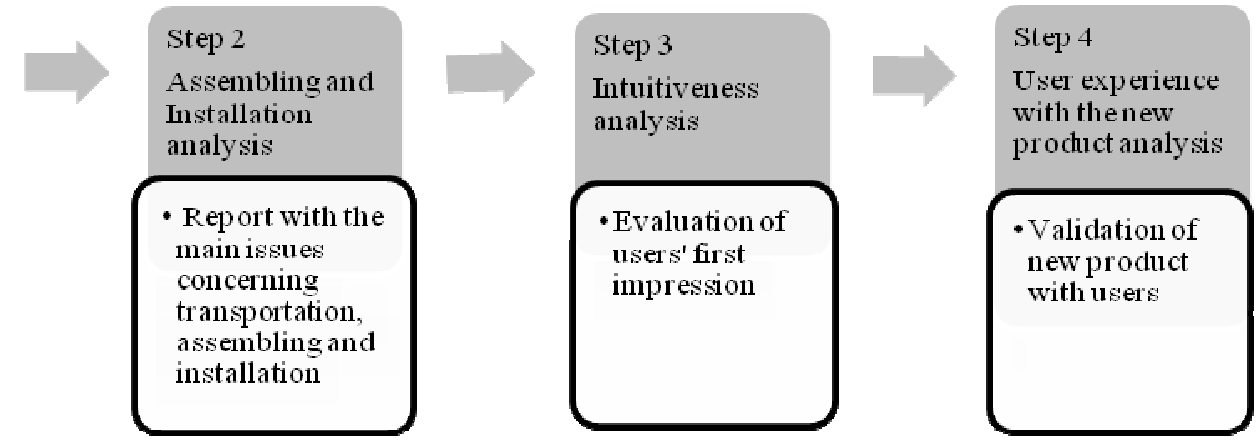

Figure 1. The four phases of the case study

\section{Results}

As previously said, this project has been focused on the company under two interaction perspectives: assembling and final user. Therefore we highlighted the most striking points during the development of the project and also in the processes of the company.

\subsection{Modularity}

This modularity concept (Figure 2) was developed based on facts and testimonials from the assemblage team that had big problems related to this factor in the old line.

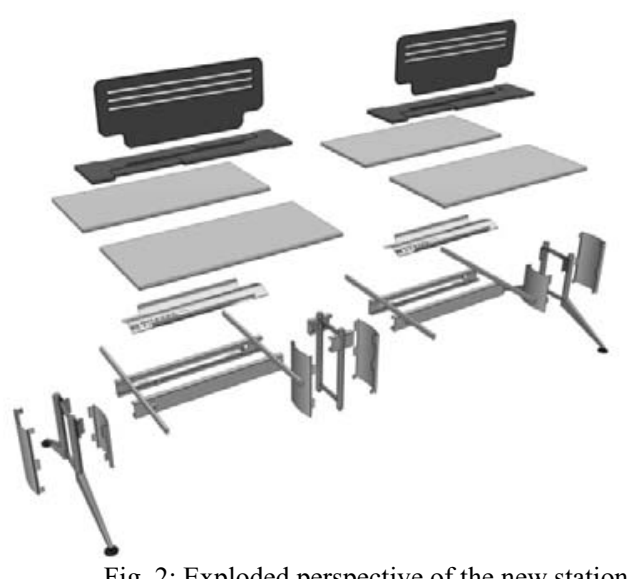

Fig. 2: Exploded perspective of the new station
During the analysis process that occurred in phase two the design team could verify in practice the difficulties of the assemblage team to transport, assemble and/or disassemble the old station. The former project had parts that were up to 3 meters long and these dimensions generated great difficulties during transportation. In the case of buildings they could not be transported using elevators. In situations like these the assembly team used to use emergency stairs but still with great difficulty as showed in Figure 3.
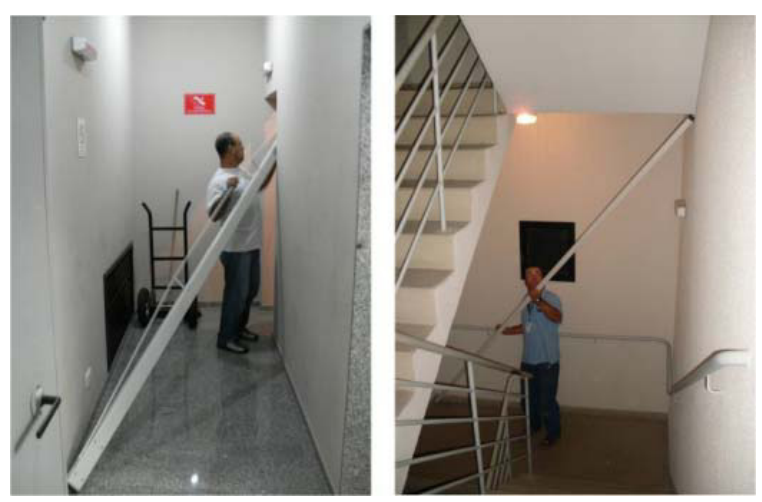

Figure 3: Difficulties on transport of old station

During observations designers could find that the changes helped and improved the performance of the workers responsible for assembly and installation, that in this new product model they gained more 
autonomy and agility while performing their work (Figure 4).
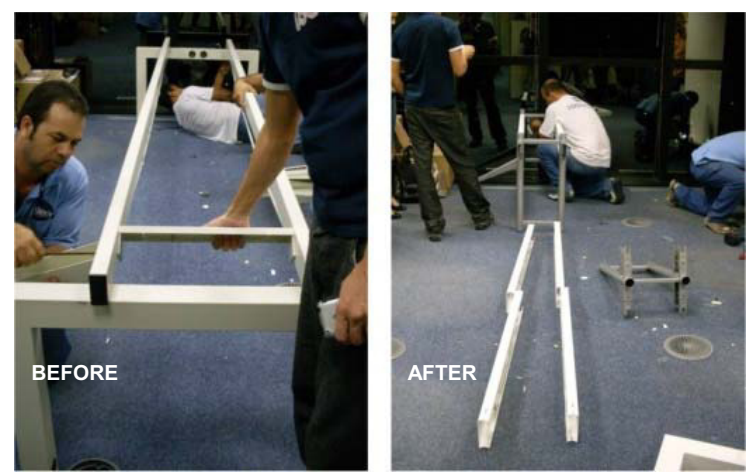

Fig. 4: Before: three men to disassemble the old station and After: one men assembling the new station

\subsection{Organization of personal objetcs}

A problem detected with a user of the workstation called the attention of various team members in phase one of Contextual Analisys (Figure 5). Her purse was always hang on the arm of the chair, an inadequate place because, aside of difficulting mobility, interrupted tasks as the purse fell of the chair frequently.

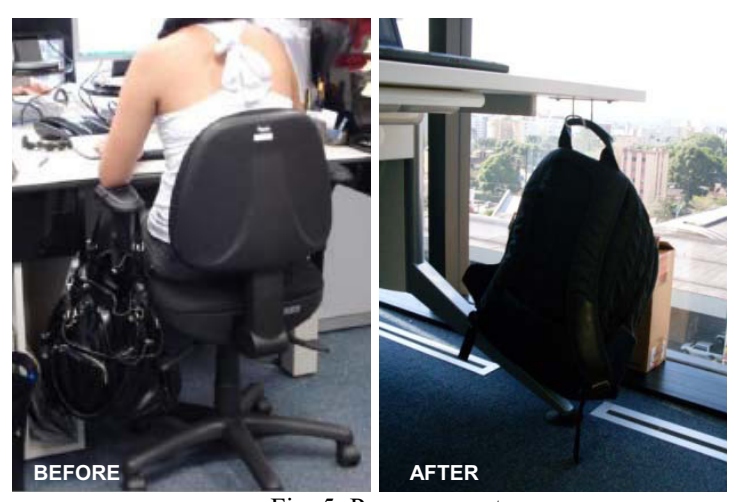

Fig. 5: Purse support

It was found that this problem wasn't limited to only one user, for the whole team had some kind of purse or bag and also didn't have a place in the room or workstation to store it. These objects were put on the desk, occupying an important space in the workstation, on the floor or, in the case of this user, hanged on the arm of the chair.

From the identification of this problem a new product was developed through a simple solution. A fixed hook under the table-top solved the organization problem, providing more freedom to the user.
The solution was approved by all users and started to integrate the accessory line of the company.

\subsection{Cable organization}

One of the most evident problem since the beginning of the project was the amount of apparent cables in the workstation and the way they were organized. Due to the way the cables were displayed and also based on users' reports, the possibility of users to twist their feet in the cables was big.
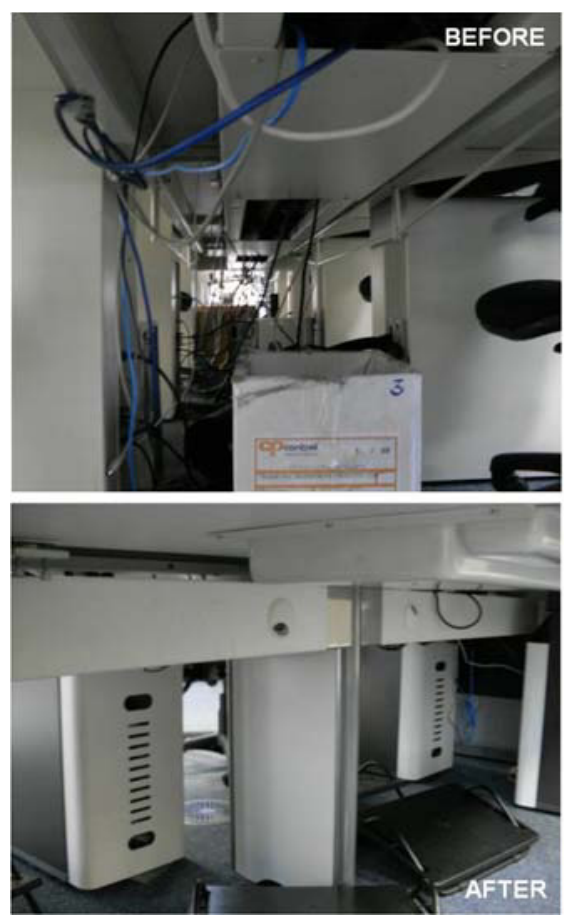

Fig. 6: Cabling, before and after

The old workstation also had a kind of organization and passage for cable. However, it wasn't practical and easy to access due to the closing lid that limited the contact of the user with the cabling and tried to hide part of these cables.

In the new workstation the cable organization was made through a new gutter system, integrated to the desk structure and also through accessories that conduct the cable to the right place (Fig. 6). Careens in the back part make the cable that come from the gutter to the computers to be stored and protected. Aside of eliminating the cable matted next to the users, it provided also a better aesthetic and visual organization in the workstation. 


\section{Conclusion}

For the company this project was a great opportunity to aggregate new knowledge. It showed that through the simple act of observing the user new ideas can come that would complete the product, turning it more adequate and satisfactory to the user.

After the first phase, were observed important points that could not be limited and points that could be improved. Therefore it was possible to provide users with a better interaction with the furnishing and at the same time to test different solutions in the same product and place.

Applying this approach of observing the user also allowed designers to analyze and review their processes and the way they were reacting to problems. With the lessons learned it was possible to improve internal processes of the company. As an example we can mention the new model of separating and sending the hardware. This process needed to be reviewed for it was impacting directly the performance of the assembly team.

Something even more important and more interesting to the company were the moments of interaction, sharing experiences and knowledge with the final users. It was in one of these moments that a final user identified a problem in the cable of one of the electronic components. Through this information it was possible to correct and eliminate the problem. That was a great differential of the project because this problem was detected by a person who wasn't directly involved neither in product development nor with the company but had specific knowledge in the area and could easily identify it.

The use of user centered design techniques allowed to validate in practice along with the final users what was brought up as a hypothesis during the development phases of the product.

From the results obtained from this project the company intends to expand the uses of the techniques of User Centered Design to other products, embodying them in the process of development of all product lines.

\section{References}

[1] Beyer, H.; Holtzblatt, K.Contextual Design: Defining Customer-Centered Systems, Morgan Kaufmann, 1997.

[2] Cybis, W.;Betiol, A.H.;Faust, R. Usabilidade: conhecimentos, métodos e aplicações, Novatec, 2010, $2^{\mathrm{a}}$ edição.

[3] Holtzblatt, K.; Wendell, J.B.; Wood, S. Rapid Contextual Design: A How-to Guide to Key Techniques for User-Centered Design, Morgan Kaufmann, 2004.

[4] ISO 9241-210 (2010) Ergonomics of Human System Interaction: Human-centred design for interactive systems [previously ISO 13407 (1999)].

[5] ISO TR 18529 (2000) Ergonomics of human-system interaction - Human-centred lifecycle process descriptions. 